DOI: 10.20472/IAC.2020.053.008

\author{
SAMI KAJALO
}

Aalto University School of Business, Finland

\title{
MARKET ORIENTATION AS COMPETITIVE ADVANTAGE IN THE AGE OF CORPORATE SOCIAL RESPONSIBILITY - AN INTEGRATIVE FRAMEWORK
}

\begin{abstract}
:
The present paper focuses on creating an organizing framework that would integrate the two distinct research domains of Market Orientation and Corporate Social Responsibility. Market Orientation (MO) consists of intelligence gathering, dissemination and management's efforts to implement this new market knowledge for firm's benefit. Although there is evidence of benefits of MO, recent research also suggests that MO itself does not anymore provide superior performance. Instead MO has become a 'cost of competing'. On the other hand, there is evidence that it is difficult (or even impossible) to achieve high performance without MO. Corporate Social Responsibility (CSR) represents companies' business practices that are intended to improve societal well-being. CSR has taken its place as a key component of firms' overall strategy and its importance is represented in annual reports and corporate websites. Moreover, recent recent suggests that CSR has a small positive impact on companies' financial performance and even a positive effect on shareholder wealth. There are only few previous attemps to focus on the interplay of MO and CSR. The present paper focuses on this research gap and provides an organizing framework to facilitate further research on the interplay of MO and CSR.
\end{abstract}

\section{Keywords:}

Market Orientation, Corporate Social Responsibility, Marketing

JEL Classification: M31, M14 